\title{
Side Effects of Leukotriene Receptor Antagonists in Asthmatic Children
}

\author{
Semiha Bahceci Erdem, ${ }^{1}$ Hikmet Tekin Nacaroglu, ${ }^{1,}$ Canan Sule Unsal Karkiner, ${ }^{1}$ Ilker \\ Gunay, ${ }^{1}$ and Demet Can $^{1}$ \\ ${ }^{1}$ Department of Pediatric Allergy, Dr. Behcet Uz Children's Hospital, Izmir, Turkey \\ ${ }^{*}$ Corresponding author: Hikmet Tekin Nacaroglu, Department of Pediatric Allergy, Dr. Behcet Uz Children’s Hospital, Izmir, Turkey. Tel: +90-2324892315, Fax: +90-2324116319, \\ E-mail: tekin212@gmail.com
}

Received: August 4, 2015; Accepted: August 16, 2015

Background: Leukotriene receptor antagonists (LTRAs) are drugs which have been widely used more than ten years. As the use of LTRAs increases, our knowledge with respect to their side effects increases as well.

Objectives: The objective of our study was to evaluat the observed side effects of LTRAs used in patients with astma.

Patients and Methods:1024 patients treated only with LTRAs owing to asthma or early wheezing were included in the study for a five-year period. The observed side effects of LTRAs in these patients were retrospectively investigated. The side effects were divided into two parts as psychiatric and non-psychiatric.

Results: Among the 1024 cases included in the study, $67.5 \%$ of the patients out of 41 with side effects were male, $32.5 \%$ were female and the average age was 6.5 years. The rate of patients with asthma was $63.41 \%$ and $36.58 \%$ of the patients had early wheezing. It was determined that sex, age and diagnosis (early wheezing or asthma) of the patients were ineffective in the emergence of side effects. The average period for the emergence of side effects was the first month. It was observed that hyperactivity was the most frequently observed psychiatric side effect and that abdominal pain was the non-psychiatric side effect.

Conclusions: The side effects of LTRAs were common in children. Therefore, patients must be informed at the beginning of the treatment and they must be evaluated at certain intervals.

Keywords: Asthma; Children; Leukotriene Receptor Antagonists; Side Effect; Wheezing

\section{Background}

Leukotriene receptor antagonists have been the first effective drugs included in asthma treatment for almost 20 years (1). They are recommended for patients with mild persistent asthma in the first step and they are included in the treatment of patients with medium persistent asthma who in order to avoid increased inhaled steroid doses for cases which cannot be taken under control. A recent review on safety and tolerability of montelukast in children with both episodic (viral) and persistent multi-trigger wheeze concluded that its safety profile is comparable to that of placebo (2). Several clinical trials emphasized that montelukast can be considered as a safe drug. However, recent evidence reconsidered the benefit/risk ratio of the use of leukotriene receptor antagonists for both pediatric and adult patients (3). Both psychiatric and non-psychiatric side effects are reported in increasing ratios. The more frequently they are used, the more information we have about their side effects. Side effects related with LTRA will be decreased when risk factors of LTRAs are determined and alternative treatment methods are applied on patients with risks in terms of side effects.

\section{Objectives}

The objective of this study was to evaluate the side effects of leukotriene receptor antagonists used on asthma patients.

\section{Patients and Methods}

1024 cases from among the 13857 with early wheezing and asthma followed up at Dr Behcet Uz Children's Hospital, Allergy Department during 2008-2013 who met the inclusion criteria were included in this study. Asthma diagnosis and classification were all performed using the Global Strategy for Asthma Management and Prevention guidelines developed by the Global Initiative for Asthma (GINA) (3). The European Respiratory Society (ERS) classification was used to identify children with episodic wheezing (4). The side effects of leukotriene receptor antagonists observed in these patients were retrospectively examined. The findings were regarded as side effects which were absent prior to the treatment of leukotriene receptor antagonists but appeared during the treatment and revealed when they were discontinued only to reappear after the treatment was initiated. Side effects were questioned in terms of their qualities and when they appeared after the interviews carried

Copyright (C) 2015, Growth \& Development Research Center. This is an open-access article distributed under the terms of the Creative Commons Attribution-NonCommercial 4.0 International License (http://creativecommons.org/licenses/by-nc/4.0/) which permits copy and redistribute the material just in noncommercial usages, provided the original work is properly cited. 
out face-to-face with the families involved and divided into two groups as early ( $<1$ week) and late $(>1$ week) side effects as to when they emerged. In addition, side effects were categorized into two parts as psychiatric and nonpsychiatric according to their systemic existence.

Inclusion criteria for the study were 1) existence of early wheezing or asthma, 2) categorization of episodic wheezing or mild persistent asthma, 3) only LTRAs use as an antiinflammatory therapy, 4) unavailability of determined findings before the use of drugs and disappearance of them after discontinuation of drugs; observation of the same side effect with the reuse of them, 5) no use of any other drugs even bronchodilator, when findings were observed.

\subsection{Statistical Analysis}

"Statistical Package for the Social Sciences" version 15.0 was used in statistical analyses. Chi-squared test was used to compare grouped data. The paired t-test was used to compare group-specific measurements and the independent Student's t-test to compare measurements among independent groups. P-values $<0.05$ were considered statistically significant.

\section{Results}

It was determined among the 1024 cases that $67.5 \%$ of the patients out of 41 with side effects were male, $32.5 \%$ were female and the average age was 6.5 years. It was indicated that $53.66 \%$ of the patients were children who were aged 5 -years-old and under. 26 patients (63.41\%) were under follow up from asthma and 15 (36.58\%) from early wheezing. It was determined that sex, age and diagnoses (early wheezing or asthma) of the patients were ineffective in the occurrence of the disease $(p>0.05)$. The occurrence time of side effects was questioned according to the statements of their families and it was identified that there were more common early side effects in 32 (\%78) patients.

It was observed that when drugs were discontinued in patients with side effects they entirely disappeared and the same effects reappeared with the initiation of drugs. 24 (58.53\%) side effects were psychiatric and they were ranked as hyperactivity, oversleep, nyctophobia and nervousness (Table 1). Non-psychiatric side effects were observed in 17 (41.46\%) patients and convulsion was was observed in 2 patients. Patients with asthma who applied to a health center due to convulsion after they had started to use leukotriene receptor antagonists applied to our center when the same findings reappeared after a while since leukotriene receptor antagonists were not taken into consideration as their side effects. Even though they were evaluated as side effects for convulsion etiology; neurological examination, biochemistry, electroencephalogram (EEG) and Cranial Magnetic resonance imaging (MRI) were carried out and no anomaly was established. Two cases were neurologically followed as asymptomatic.
Table 1. Side Effetcs Regarding Leukotriene Receptor Antagonists Use in Children With Asthma

\begin{tabular}{lc}
\hline Variable & Values $^{\text {a }}$ \\
\hline Psyhchiatric & $24(58.53)$ \\
\hline Hyperactivity & $7(17)$ \\
\hline Excessive sleepiness & $4(9.7)$ \\
\hline Nyctophobia & $4(9.7)$ \\
\hline Nervousness, agitation & $4(9.7)$ \\
\hline Hallucination & $4(9.7)$ \\
\hline Sleep disorder, depression & $1(2.4)$ \\
\hline Nonpsychiatric & $17(41.46)$ \\
\hline Abdominal pain & $6(14.6)$ \\
\hline Rash & $3(7.3)$ \\
\hline Aphtous ulcers & $2(4.8)$ \\
\hline Increased appetite & $1(2.4)$ \\
\hline Headache & $3(7.3)$ \\
\hline Convulsion & $2(4.8)$ \\
\hline
\end{tabular}

a The values presented as No. (\%).

\section{Discussion}

Leukotrienes were discovered with the examination of compounds mixture known SRS-A or a substance of anaphylaxis which reacts slowly. Cysteinyl leukotrienes, namely, leukotriene $\mathrm{C} 4$ and its biologically active metabolites LTD4 and LTE4 were found in 1980 (6). In comparison with histamine, LTC4 is 600-9500 times more effective, howeverLTD4 is 6000 times more powerful (7). Respiratory airways of patients with asthma are 14 - 219 times more susceptible to histamine, metacholinium, LTC4, LTD4 and LTE4 in comparison to normal individuals (8). Montelukast sodium is a selective leucotriene receptor antagonist (LTRA) that specifically blocks the cysteinyl leucotriene type 1 (CysLT1) receptor. CysLTs (LTC 4, LTD 4 and LTE 4) are important pro-asthmatic lipid mediators binding to CysLT receptors. The CysLT1 receptor is localized in human airways and synthesized by a variety of cells, including mast cells, eosinophils, basophils and macrophages (9). CysLTs have been correlated with the pathophysiology of asthma and allergic rhinitis (3).

Leukotriene antagonists are classified in two groups; experience regarding the use of drugs inhibiting leukot- 
riene synthesis of the first group is quite low in children. LTRAs are found in the other group and montelukast and zafirlukast are commonly observed in the children of this group. It was shown in studies performed with montelukast and zafirlukast that they ameliorated the quality of life and that respiratory functions and their side effects were indistinguishable than those of placebo $(6,10,11)$. Montelukast reaches its peak plasma concentration in 3 hours time. Ninety-nine percent of it binds with plasma proteins. Foods do not affect its oral absorption. Both the drug and its metabolites plunge through the bile (12).

Anti-inflammatory therapy, consisting mainly of inhaled corticosteroids (ICS), is the corner stone of asthma management. Since Leukotrienes (LTs) are chemical mediators of airway inflammation in asthma, LTRAs are traditionally used as potent anti-inflammatory drugs in the long-term treatment of asthma in adults, adolescents, and school-age children. Leukotriene receptor antagonists are effective in young children with virusinduced wheeze, with multiple-trigger disease and exercise induced asthma in children (13-18). In addition, the use of montelukast and pranlukast was approved by Food Drug Administration (FDA) in the treatment of rhinitis (19).

Several recent studies have addressed the use of leukotriene receptor antagonists as monotherapy as well as in combination with other first line therapies for chronic urticaria (20). A Cochrane review, comparing long-acting beta-2 agonists versus anti-leucotrienes (including montelukast) in children and adults on regular treatment with inhaled corticosteroids, stated that anti-leucotrienes caused less incidences of serious adverse events compared to long-acting beta-2 agonists (21). Although anti-leucotrienes are generally well-tolerated, several case reports have been published that describe adverse drug reactions following the use of montelukast (3). Most of the adverse events described are mild (headache, gastrointestinal disorders, pharyngitis, fatigue, upper respiratory tract infection, cutaneous rash and reversible alterations in levels of serum transaminase) and do not significantly differ from those described in subjects receiving placebo $(3,15)$. Churg-Strauss syndrome depending on LTRAs was also reported $(3,22,23)$. The possible role of leukotriene receptor antagonist therapy in the pathogenesis of Churg-Strauss syndrome is still uncertain. All patients only showed symptoms following the start of the therapy and symptoms seemed to remit after the medication was withdrawn. Churg-Strauss syndrome affects especially adult patients of both genders. When Churg-Strauss syndrome cases related with montelukast were examined, it was stated that contrary to the side effects of other drugs, the cases generally finalize with sequel despite withdrawing the drug and carrying out the required treatment (3). None of the patients experienced the Churg- Strauss syndrome.

Xie et al. (23) observed montelukast-induced haematuria in a 58-year-old female patient. Her gross haematuria improved 7 days after montelukast withdrawal. Her renal functions returned to normal two weeks later. None of the patients reported haematuria.

Skin and subcutaneous tissue disorders such as leukotriene receptor antagonists related angio-oedema, bruising, erythema nodosum, pruritus, rash and urticaria may be reported. Urticeria was observed as a skin symptom in 3 (7.3\%) of our studies. Skin symptoms disappeared completely within 1 to 7 days following the withdrawal of the medicine. Oral aphthous lesion was not determined in 2 $(\% 4,8)$ of our patients. This side effect that recovers when the drug is withdrawn but reappears when drug administration is started again has not been stated previously. LTRA relatedoral aphthous lesion recovered completely during the week in which the drug was withdrawn.

Zileuton is associated with a modest incidence of headache and dyspepsia but hepatotoxicity, was reported in $1.9 \%$ of patients. Hepatotoxicity is a direct toxic effect of the drug rather than the consequence of 5-LO inhibition. Aminotransferase increase was generally reported in the first 8 weeks of the treatment and it was observed that it was temporary, asemptomatic and that it was revealed rapidly $(6,24)$. The recommended monitoring strategy includes monthly alanine aminotransferase checks for the first 3 months, every 2 - 3 months for the remainder of the first year and yearly thereafter $(6,24)$. Montelukast can cause hepatobiliary and pancreatic dysfunction. Notably, it has been described in a case of fatal hepatotoxicity; however, in this case it was not possible to describe the mechanism that triggered hepatotoxicity. Interestingly, various experimental models of drug induced hepatotoxicity in rats showed a protective effect of montelukast (3). It was stated in 2007 that a patient died due to fatal hepatitis related with citrus aurantium, Garcinia cambogia extracts and montelukast treatment. Excluding this patient, it is stated that LTRA related hepatitis generally recovers following the withdrawal of the drug (3). Palodhi et al. (25) observed the case of a male patient who developed hypertriglyceridemia and associated lipid profile abnormalities following the administration of montelukast. Hypertriglyceridemia can be detrimental not only for individuals with a cardiovascular risk profile but also for healthy subjects so blood values should be monitored in every patient on montelukast therapy. It is stated that triglyceride values regress to the baseline level following the withdrawal of the drug in cases with hypertriglyceridemia (3). It is also stated that LTRA related pancreatitis is recovered completely in 22 year old patients following the withdrawal of the drug (26). Biochemical evaluation of hepatotoxicity could not be carried out since the study was retrospective. However, hepatoxicity that might cause clinical findings was not observed in our patients.

Evidence of the presence of CysLT1 in the brain suggests that the pathway of CysLT receptors is more complex than it was initially supposed. Various pre-clinical experiments that explore the function of this pathway in the central nervous system reveals an over-expression in the 
reparative process occurring during particular pathological conditions (27). Even though studies on children are lacking, it could be hypothesized that, in susceptible pediatric patients, blocking CysLT1 by its specific antagonists can cause neuropsychiatric adverse reactions.

Agitation including aggressive behaviour or hostility, anxiousness, depression, disorientation, dream abnormalities, hallucinations, insomnia, irritability, restlessness, somnambulism, suicidal thinking and behavior (suicidality), tremor, dizziness, drowsiness, araesthesia/ hypoesthesia, sleep talking, sleepwalking, and very rarely seizures were reported during the postmarketing surveillance of montelukast (3). Patients with psychiatric disorders may have a predisposition for the side effectss of montelukast (28). While hyperactivity was the most frequently seen psychiatric side effect, abdominal pain was most common as non-psychiatric side effect in our study. Another interesting feature of our study was that convulsion related with leukotriene receptor antagonists was observed in 2 of our patients even though leukotriene receptor antagonist related convulsion is rarely reported. No abnormality was detected in the patients in whom particularly non-psychiatric side effects (headache and convulsion) were seen when other etiological factors that could lead to the findings were analyzed. Convulsions were not related with leukotriene receptor antagonists in both cases with convulsions; convulsion did not repeat in both cases following the re-initiation of leukotriene receptor antagonists after discharge. Leukotriene receptor antagonists were withdrawn in both cases and no more seizures were observed. These cases are still under follow up with no convulsions. It is claimed that the neuropsychiatric manifestations reported in older children during montelukast treatment were never been observed in preschool age (17). Nevertheless, although in our study more than half of the cases were in preschool age, neuropsychiatric manifestations were observed.

Psychiatric side effects reported during the therapy of children $<18$ using LTRA were studied in Sweden between 1998 - 2007 and according to their frequency sequence, they were stated as nyctophobia, aggressiveness, anxiety, sleep disorders, insomnia, irritability, hallucination, hyperactivity and personality changes. Depression, apathy, persistent cry, concentration disorder, amnesia and depersonalization were reported with a lower frequency rate. The side effects appeared in the first week following the initiation of medicine in $80 \%$ of the cases $(1,29,30)$. In the present study, side effects often emerged in early period.

It was reported in a study conducted by Zhou et al. (31) that antidepressant requirement significantly increased compared to other age groups after montelukast was commenced in patients ranging from 18 -24. Celmeli et al. (32) reported a 13 year old male case who had no genetic predisposition or psychological problems but who put forth depression and suicidal thinking/behavior following the use of montelukast for which all complaints stopped completely following the withdrawal of the drug. Bygdell et al. (33) reported that montelukast was among the first three drugs of which psychiatric side effects were most frequently observed in those of younger age than 18 in 2012. In our study carried out with this treatment agent that was regarded to be indifferent from placebo, a high (4\%) rate of side-effects was observed.

The most important limit in our study was that for psychiatric side effects psychiatric evaluation of patients had not been carried out prior to treatment onset. A randomizedcontrolled prospective study will fill the gap in this area.

Consequently, both psychiatric and non-psychiatric side effects were observed in our patients depending on the use of leukotriene receptor antagonists. The most commonly observed were psychiatric problems. The patients should be evaluated with regard to psychiatric problems as well as additional accompanying disorder prior to the treatment. Physicians should be aware of adverse drug reactions during their clinical practices and should take into account that the administration of montelukast, along with concomitant therapies, may increase the risk of drug-drug interaction. Patients should be informed in this respect and they should be assessed at certain intervals following the initiation of the treatment with leukotriene receptor antagonists. Moreover, comprehensive studies for determining the risk factors for leukotriene receptor antagonists related adverse drug reactions should be carried out.

\section{Acknowledgements}

We would like to thank the nurses and workers in our department of pediatric allergy who helped us during this work.

\section{References}

1. Kocyigit A, Gulcan Oksuz B, Yarar F, Uzun F, Igde M, Islek I. Hallucination development with montelukast in a child with asthma: case presentation. Iran J Allergy Asthma Immunol. 2013;12(4):397-9.

2. Bisgaard H, Skoner D, Boza ML, Tozzi CA, Newcomb K, Reiss TF, et al. Safety and tolerability of montelukast in placebo-controlled pediatric studies and their open-label extensions. Pediatr Pulmonol. 2009;44(6):568-79.

3. Calapai G, Casciaro M, Miroddi M, Calapai F, Navarra M, Gangemi S. Montelukast-Induced Adverse Drug Reactions: A Review of Case Reports in the Literature. Pharmacology. 2014;94(1-2):60-70.

4. Global strategy for asthma management and prevention. Global Initiative for Asthma (GINA) 2014 (revised), available from: http:/ www.ginasthma.org.

5. ERS task force. Definition, assessment and treatment of wheezing disorders in preschool children: an evidence-based approach. Eur Respir J. 2008;32(4):1096-1110.

6. Drazen JM. Leukotriens, Asthma and Rinitis. United States: Blackwell Scientific Publications; 1995. pp. 838-50.

7. O'Byrne PM. Leukotrienes in the pathogenesis of asthma. Chest. 1997;111(suppl):27-34.

8. Peters-Golden M. Gleason MM. Togias A. Cysteinyl leukotrienes: multi-functional mediators in allergic rhinitis. Clin Exp Allergy. 2006;36(6):689-703.

9. Nelson H, Kemp J, Berger W, Corren J, Casale T, Dube L, et al. Efficacy of zileuton controlled-release tablets administered twice daily in the treatment of moderate persistent asthma: a 3-month 
randomized controlled study. Ann Allergy Asthma Immunol. 2007;99(2):178-84.

10. Kraft M, Cairns CB, Ellison MC, Pak J, Irvin C, Wenzel S. Imrovements in distal lung function correlate with asthma symptoms after treatment with oral montelukast. Chest. 2006;130(6):1726-1732.

11. Mandeep W, Rakesh L, Kabra SK. Montelukast in Pediatric Asthma Management. Indian J Pediatr. 2006;73(4):275-82.

12. Price D, Musgrave SD, Shepstone L, Hillyer EV, Sims EJ, Gilbert RF, et al. Leukotriene antagonists as first-line or add-on asthma-controller therapy. NEngl J Med. 2011;364(18):1695-707.

13. Baumgartner RA, Martinez G, Edelman JM, Rodriguez Gomez GG Bernstein M, Bird S, et al. Distribution of therapeutic response in asthma control between oral montelukast and inhaled beclomethasone. Eur Respir J. 2003;21(1):123-8.

14. Robinson DS, Campbell D, Barnes PJ.Addition of leukotriene antagonists to therapy in chronic persistent asthma: a randomised double-blind placebo-controlled trial. Lancet. 2001;357(9273):2007-11.

15. Wahn U, Dass SB. Rewiev of recentresults of montelukastuse as a monotherapy in children with mild asthma. Clin Ther. 2008;30:1026-35.

16. Montella S, Maglione M, De Stefano S, Manna A, Di Giorgio A, Santamaria F. Update on leukotriene receptor antagonists in preschool children wheezing disorders. Ital J Pediatr. 2012;38:29.

17. Bisgaard H, Zielen S, Garcia-Garcia ML, Johnston SL, Gilles L, Menten J, et al. Montelukast reduces asthma exacerbations in 2- to 5-year-old children with intermittent asthma. Am J Respir Crit Care Med. 2005;171(4):315-22.

18. Peters-Golden M, Swern A, Bird SS, Hustad CM, Grant E, Edelman $J M$. Influence of body mass index on the response to asthma controller agents. Eur Respir J. 2006;27(3):495-503.

19. Silva NL, Damayanthi H, Rajapakse AC, Rodrigo C, Rajapakse S. Leukotriene receptor antagonists for chronic urticaria: a systematic review. Allergy Asthma Clin Immunol. 2014;10(1):24

20. Chauhan BF, Ducharme FM. Anti-leukotriene agents compared to inhaled corticosteroids in the management of recurrent and or chronic asthma in adults and children. Cochrane Database Syst Rev. 2012;16:5.CD002314.

21. Philip G, Malmstrom K, Hampel FC, Weinstein SF, LaForce CF, Ratner $\mathrm{PH}$, et al. Montelukast for treating seasonal allergic rhinitis: a randomized, double-blind, placebo-controlled trial performed in the spring. Clin Exp Allergy. 2002;32(7):1020-8.

22. Wechsler ME, Pauwels R, Drazen JM. Leucotriene modifiers and Churg-Strauss syndrome: advers effect or response to corticosteroid with drawal? Drug Saf. 1999;21(4):241-251.

23. Xie JX, Wei JF, Meng L. Montelukast sodiuminduced hematuria: a case report and literature review of 19 cases in mainland China. Int J Clin Pharmacol Ther. 2013;51(12):958-962.

24. Cuchacovich R, Justiniano M, Espinoza LR. Churg-Strauss syndrome associated with leukotriene receptor antagonists (LTRA). Clin Rheumatol. 2007;26(10):1769-71.

25. Palodhi S, Ray Chaudhuri P, Biswas A, Bera T. Montelukast induced hypertriglyceridemia. Indian Med Gaz. 2012;146:334-336.

26. Das S, Mondal S, Dey JK, Bandyopadhyay S, Saha I, Tripathi SK. A case of montelukast induced hypercholesterolemia, severe hypertriglyceridemia and pancreatitis. J Young Pharm. 2013;5(2):64-66.

27. Ding Q, Fang SH, Zhou Y, Zhang LH, Zhang WP, Chen Z, et al. Cysteinyl leukotriene receptor 1 partially mediates brain cryoinjury in mice. Acta Pharmacol Sin. 2007;28(7):945-952.

28. Philip G, Hustad CM, Malice MP, Noonan G, Ezekowitz A Reiss TF, et al. Analysis of behavior-related adverse experiences in clinical trials of montelukast. J Allergy Clin Immunol. 2009;124(4):699-706.

29. Dube LM, Swanson LJ, Awni W. Zileuton, a leukotriene synthesis inhibitor in the management of chronic asthma: clinical pharmacokinetics and safety. Clin Rev Allergy Immunol.1999;17(1-2):213-221.

30. Wallerstedt SM, Brunlof G, Sundstrom A, Eriksson AL. Montelukast and psychiatric disorders in children. Pharmacoepidemiol Drug Saf. 2009;18(9):858-64

31. Zhou EH, Kaplan S, Mosholder A, Moeny D, Ding Y, Wu Y, et al. Antidepressant medication dispensing among montelukast initiators. J Asthma. 2013;50(9):990-5.

32. Celmeli F, Celmeli G, Surer Adanır A, Türkkahraman D. Suicide Behaviour After Montelukast Usage: A Case Report. Turkish Journal of Pediatric Disease. 2014;4(8):212-214.

33. Bygdell M, Brunlöf G, Wallerstedt SM, Kindblom JM. Psychiatric advers drug reactions reported during a 10-year period in the Swedish pediatric population. Pharmaco epidemiol Drug Saf. 2012;21(1):79-86 